\title{
The relationship between price and financial stability in new monetary policy designs: the case of the US using the TVP-SVAR model*
}

La relación entre estabilidad de precios y financiera en nuevos diseños de política monetaria: el caso de Estados Unidos usando un modelo TVP-SVAR

\author{
ÖMER YALÇINKAYA** \\ Ali Kemal Çelí**** \\ HATIRA SADEGHZADEH EMSEN****
}

\begin{abstract}
This study aims to explain the relationship between price and financial stability in monetary policy designs that have developed since the 1990s and to empirically examine the relationship between price and financial stability in the monetary policy designs of the US. To this effect, the study examines the time-varying structure of the relationship between price and financial stability in the US, where monetary policies are designed to achieve price stability, full employment and moderate long-term interest rate targets using the TVP-SVAR model for the period 1993:12-2020:12. The results of the study demonstrate the presence of a reciprocal relationship within the scope of the new environment hypothesis, which varies over time between price and financial stability in the US over the study period. These results broadly suggest the necessity of redesigning monetary policies in the US based on the propositions of the new environment hypothesis and considering the varying structure of the relationships, symmetrical or asymmetrical, between monetary and financial stability variables over time.
\end{abstract}

Key words: Monetary policy designs, new environment hypothesis, US, TVP-SVAR.

JEL Classification: B40, C58, E44, E52.

* The authors are grateful to Prof. Rómulo Chumacero, Editor-in-Chief of Estudios de Economía, and the anonymous referees for their constructive remarks that have significantly improved the manuscript.

** Department of Economics, Atatürk University, Erzurum, Turkey. E-mail: oyalcinkaya@ atauni.edu.tr

*** Corresponding author, Department of Quantitative Methods, Ardahan University, Ardahan, Turkey. E-mail: alikemalcelik@ardahan.edu.tr

**** Independent Researcher, E-mail: sadeghzadeh.khatereh@gmail.com

Received: December, 2020. Accepted: August, 2021. 


\section{Resumen}

Este trabajo pretende explicar la relación entre estabilidad de precios y financiera en nuevos diseños de política monetaria desarrollados desde los noventas y examinarla empíricamente para el caso de Estados Unidos. Para ello se examina una estructura variante en el tiempo usando un modelo TVP-SVAR para el periodo 1993:12-2020:12. Se encuentra una relación variable en el tiempo entre estabilidad de precios y financiera. Estos resultados sugieren la necesidad de rediseñar la política monetaria.

Palabras clave: Diseño de política monetaria, TVP-SVAR.

Clasificación JEL: B40, C58, E44, E52.

\section{INTRODUCTION}

Since the global financial crisis (GFC) of 2008-09, global economic growth has been propelled mainly by expansionary monetary policies, with advanced countries in exemplary positions, and has maintained a fixed rate of approximately $2-3 \%$ for the past few years (IMF, 2020). Despite the moderate recovery in global economic growth supported mainly by expansionary monetary policies and significantly low policy interest rates after the GFC, the stance of monetary policies remains extraordinarily accommodative when combined with low inflation rates below the target (Nair \& Anan, 2020).

The ongoing expansionary monetary policies and the resulting increases in investor risk appetite lead to the accumulation of systemic risks in financial markets and thereby force a tight monetary policy stance. This emerging conjuncture in the global economy approximately ten years after the GFC not only reminds us of the global economic outlook in the pre-GFC period but also shows the difficulties faced by the central banks in designing monetary policies during a period of crisis (Fouejieu et al., 2019). This view of the global economy after the GFC leads to the questioning and redesigning of traditional monetary policies based on inflation targeting, which have been implemented by a significant portion of central banks of both developed and developing countries since the 1990s (Smets, 2014; Sahoo, 2020). Thus, the GFC has reduced the effectiveness of policies that assume that in both developed and developing countries where output and inflation deficits are relatively balanced, the central bank's adjusted interest rates based on output and inflation deficit are compatible in ensuring price and financial stability (Mishkin, 2011; Fouejieu, 2017). Consequently, the GFC shows that even if price stability is achieved, there can be bubbles in financial asset prices, and the interest rates to achieve price and financial stability might not be compatible. Thus, financial risks cannot be eliminated only by monetary policies and instruments that enhance price stability (Borio, 2014; Kim \& Mehrotra, 2017). 
In these post-GFC conditions, central banks of both developed and developing countries should redesign their monetary policies to include instruments that can limit the effects of financial risks on output and inflation deficits and achieve financial stability without sacrificing price stability (Özatay, 2012; Roldán-Peña et al., 2017). In these new monetary policy designs, central banks should seek to limit the effects of financial risks on output and inflation deficits with micro/ macro prudent measures and also ensure that price stability supports financial stability (Karanovic \& Karanovic, 2015; Sethi \& Acharya, 2020). The theoretical foundations of these emerging new monetary policy designs after the GFC are based on the "new environment hypothesis" proposed in a study by Borio \& Lowe (2002) just before the GFC. The "new environment hypothesis" criticizes traditional monetary policy designs within the framework of "The Conventional Wisdom Hypothesis" introduced by Schwartz (1995), which posits that price stability can provide financial stability. It states that price stability might not necessarily guarantee financial stability and that it is possible for price and financial stability to be observed concurrently in monetary policy designs (Issing, 2003).

To explain the relationship between price and financial stability of monetary policy designs since the 1990s, this study empirically examines the relations between price and financial stability in the monetary policy designs of the United States of America using nonlinear time series analysis. Following this objective, the time-varying nature of the relationship between price and financial stability in the US for the period 1993:12-2020:12 is econometrically analyzed using the time-varying parameter structural vector autoregression (TVP-SVAR) model. The TVP-SVAR model allows us to observe nonlinear trends in the relations between price and financial stability in the 1993:12-2020:12 period in the US and to examine the effects of timing (specific periods and maturities) in monetary policy designs. Thus, the relationship between price and financial stability in the US in the 1993:12-2020:12 period can be examined econometrically, before the GFC, when monetary policy designs developed, and after the GFC, where they changed significantly. To this effect, the US's financial stability variables measured in the form of an index encompassing various indicators of financial markets and price stability measured on the difference of actual inflation rates from the mean are used. In the US, where monetary policies were designed by the Federal Reserve System (FED) in line with the main objectives of price stability, full employment and moderate long-term interest rate, the time-varying structure of the relationship between price and financial stability in the 1993:122020:12 period was empirically analyzed with the TVP-SVAR model. This study constitutes the main purpose and motivation of this study. In this context, the research question of the study consists of econometrically testing whether the time-varying structure of the relations between price and financial stability in the US during the examination period (in certain years and maturities) can be explained by the traditional wisdom and/or new environment hypotheses. This study contributes to growing theoretical debates on monetary policy designs since the 1990s and the empirical studies that have emerged in the available literature after the GFC in three strands. 
First, the study investigates the empirical validity of the theoretical explanations of the relationship between price and financial stability in monetary policy designs in the US for the period 1993:12-2020:12 within the scope of the traditional wisdom and/or new environment hypotheses. Therefore, the study intends to empirically determine the relationship between price and financial stability in the US during the sampling period and to determine the optimal level of the relationship between price and financial stability in the monetary policy designs of the US. Second, price stability is represented by the differences in the inflation rates from the mean, and financial stability is represented by variables in the form of an index. However, in the empirical literature, price stability is usually included in the econometric analysis, with more direct variables measured over actual inflation rates, while financial stability is measured through indicators such as the exchange rate, stock prices, financial sector loans, and other factors. Third, unlike studies that generally investigate the relationships between price and financial stability with a linear VAR model within the scope of time series analysis in the empirical literature, this study applies a nonlinear TVP-SVAR model to examine the varying nature of the relationships between price and financial stability over time. Therefore, the nonlinear trends of price and financial stability variables during the review period can be observed and examined to determine whether the timing before, during and after the GFC is important in discussing the relationship between price and financial stability.

In the second section after the introduction, the theoretical and empirical literature on the relationship between price and financial stability is presented, and the position of the study in the context of the extant literature is explained. In the third section, the econometric approach and the methodology of the study and data set are introduced. In the fourth section, the interaction between price and financial stability in the US for the period 1993:12-2020:2 is examined within the framework of the TVP-SVAR model, and the empirical findings of the study are discussed. In the last section, empirical findings and policy implications of the study are discussed, and recommendations for future studies are presented.

\section{THE RELATIONSHIP BETWEEN PRICE AND FINANCIAL STABILITY: THEO- RETICAL FRAMEWORK AND EMPIRICAL LITERATURE}

\subsection{Theoretical framework}

The relations between price and financial stability in monetary policy designs have become an important policy agenda after the GFC. However, two different approaches that offer explanations for this mechanism have been documented in the theoretical literature since the 1990s. The first of these approaches is the "Traditional Wisdom Hypothesis" developed by Schwartz (1995). Schwartz (1995) posits that price stability supports and strengthens financial stability. The second approach is the "new environment hypothesis" proposed by Borio \& Lowe (2002) and Borio et al. (2003), which posits that price stability might 
not guarantee financial stability (Issing, 2003). Schwartz (1995) mentioned that monetary policy practices that cause price instability make the information flow between parties in a debt agreement asymmetric and hence are the main causative factor of financial instability. According to Schwartz (1995), instabilities in price as a result of an increment in money supply due to expansionary monetary policies make it difficult to estimate the real returns of financial investments. This circumstance results in the excessive overvaluation or undervaluation of asset prices and thereby causes financial instabilities. It is assumed that monetary policy practices that can provide price stability can prevent such information, estimation and valuation problems and provide financial stability (Schwartz, 1995). Similarly, Bordo \& Wheelock (1998) stated that financial instability can be caused by unexpected changes in the money supply if there exists a strong correlation between price and financial stability. According to Bordo \& Wheelock (1998), increments in commodity and security (real estate) prices due to changes in money supply cause bubbles in asset prices and financial instability. Monetary policy practices that focus on controlling changes in the money supply are deemed to provide price and financial stability simultaneously (Bordo \& Wheelock, 1998). In a related study, Issing (2003) stated that a forward-looking strategy that aims at achieving and maintaining price stability in the medium-long term in monetary policy designs can also eliminate financial instabilities. This study argued that even if a short-term trade-off between the main goal of price stability and financial stability is experienced in such a future-oriented monetary policy design, such a conflicting mechanism will disappear in the medium-long term, and price stability will support financial stability (Issing, 2003). Other studies in the theoretical literature that explain the relationship between price and financial stability within the different contexts of the traditional wisdom hypothesis are Demirgüç-Kunt \& Detragiache (1998), Hardy \& Pazarbasioglu (1999), Bordo et al., (2002), and Woodford (2012).

Borio \& Lowe (2002) explained the relationship between price and financial stability from the perspective of the new environment hypothesis. They juxtaposed that financial instability can be observed even when price stability is achieved and that monetary policies should be designed in consideration of both financial stability and price stability. According to Borio \& Lowe (2002), monetary policies with high credibility can ensure price stability and improve the expectations of economic actors. The improvement in medium- to long-term expectations causes the formation of bubbles in debt asset prices and, consequently, the accumulation of systemic risks in financial markets. It is therefore assumed that monetary policy designs that do not provide for such circumstances in financial markets through the expectations channel cannot prevent but rather deepen financial instabilities (Borio \& Lowe, 2002). In its most general terms, systemic risk is defined by the International Monetary Fund (IMF), Bank for International Settlements (BIS) and the Financial Stability Board (FSB) (2009), as resulting from disruptions in some or all of the financial system and has the potential to have significant negative consequences on the real economy. It is defined as the risk of deterioration of financial services. On the basis of this 
definition, there are negative externalities that arise from malfunctions in any of the financial system elements in the form of instruments, institutions and markets, and the effects of these externalities on the real economy are emphasized (IMF-BIS-FSB, 2009).

In a related study, Rajan (2005) attributed inflation to changes in interest rates. The study argued that the basis of financial instability is the adjustments in the risk appetite of economic actors concerning changes in inflation and interest rates. According to Rajan (2005), inflation and interest rates are relatively low in an economic environment where price stability is achieved. However, the risk appetite of economic actors in such an environment with an advanced financial system increases, and they tend to use alternative tools that will provide higher returns amidst higher risks. This situation, which can plunge an economy into financial instabilities, requires that monetary policies be designed with a thorough comprehension of the factors that reduce the risk appetite of economic actors. This approach will reduce the tendency of bubbles in debt asset prices and the associated accumulation of systemic risks in financial markets over time (Rajan 2005). These findings regarding monetary policy designs also corroborate the findings of studies by Leijonhufvud (2007). Leijonhufvud (2007) states that monetary policies aiming only at reducing the changes in inflation rates and ensuring price stability cannot prevent financial instability caused by credit asset price bubbles in financial markets but can also feed them in certain periods or conditions. Under the conditions of political or market pressures on central banks and being asymmetrical, low inflation rates can harbor the formation of credit asset price bubbles, and focusing on price stability can lead to policies that could threaten financial stability in the long run. For this reason, Leijonhufvud (2007) states that it is necessary to design central banks in a way that can eliminate the negative effects of monetary policies on financial stability and to take care of financial stability in the long run as well as price stability (Leijonhufvud, 2007). Other studies documented in the theoretical literature on the relationship between price and financial stability based on different perspectives of the new environment hypothesis include White (2006), Borio (2014b), Smets (2014), and Billi and Verdin (2014). Other studies documented in the theoretical literature on the relationship between price and financial stability based on different perspectives of the new environment hypothesis include White (2006), Borio (2014b), Smets (2014), Billi and Verdin (2014).

\subsection{Empirical literature}

Although the relations between price and financial stability have been explained in the theoretical literature from the perspectives of both the traditional wisdom hypothesis and the new environment hypothesis since the 1990s, studies on the subject matter in the available empirical literature coincide with the period after the GFC. Although the empirical literature on the relationship between price and financial stability shows a certain development after GFC, there is a limited number of studies on the subject matter. An examination of the empirical 
literature reveals a study by Granville \& Mallick (2009) on countries in the Euro area as one of the pioneering studies that examine the relationship between price and financial stability. In this study, the relationships between price stability represented by the actual inflation rate and financial stability represented by various financial variables (nominal effective exchange rate, stock prices and the ratio of banking sector loans to deposits) were analyzed within the scope of time series analysis with quarterly data for the period 1994: Q1-2008: Q2. The estimation result of their analysis based on the output of the established linear vector autoregression (VAR) model shows a reciprocal relationship between price and financial stability in countries in the euro area with price stability supporting financial stability. Similarly, the results that support the validity of the traditional wisdom hypothesis on the relations between price and financial stability were found in a related study by Frappa \& Mésonnier (2010) on 17 developed OECD member countries using probit regression analysis within the scope of panel data analysis with annual data for the period 1980-2017.

Dhal et al. (2011) conducted a study on India to investigate the relationship between price stability (represented by the actual inflation rate) and financial stability (calculated in the form of an index based on various indicators related to the stability of the Indian banking sector). The study was designed within the scope of time series analysis with quarterly data covering the period 1995: Q1-2012: Q3. The result of their analysis based on the linear VAR model reveals that the relationship between price and financial stability in India is reciprocal. They found that financial stability supports price stability; however, price stability impedes financial stability. Empirical results that support the validity of the new environment hypothesis on the relationship between price and financial stability were found in studies by Blot et al. (2015) and Sethi \& Acharya (2020).

Blot et al. (2015) examined the relationship between price stability represented by the actual inflation rate and financial stability calculated in the form of an index that encompasses various indicators related to the stability of the banking and finance sector of the US and countries in the Eurozone for the period 1993: M12-2012: M12 and 1999: M1-2012: M12. The results of the analysis within the framework of dynamic conditional correlations (DCCs) and the linear VAR model reveal that the relationship between price and financial stability in the US and Europe is reciprocal. Similar to findings by Dhal et al. (2011), they found that financial stability supports price stability and that price stability impedes financial stability. Sethi \& Acharya (2020) investigated the relationship between price stability, captured as the actual inflation rate, and financial stability, represented by variables such as house prices and returns, with quarterly data from the period 1997: Q1-2016: Q3 on the Philippines, South Korea, Israel, Indonesia and Thailand. The empirical result of their analysis with a linear VAR model shows that in these five countries, where monetary policy designs are based on an inflation targeting regime, there is a negative relationship between price and financial stability, with price stability hindering financial stability. Research findings that reveal a negative relationship between price and financial stability are based on the use of Bayesian VAR and vector error correction (VEC) 
models in different periods within the scope of time series analysis. A study on Germany (Euro area) applied Bayesian VAR (Van Roye, 2011). In the context of India, the VEC (Ramesh Babu and Venkateswarlu, 2017) and VAR (Sahoo, 2020). Unsurprisingly, all these studies concluded that financial instabilities in the relevant countries negatively affect and prevent price stability.

Following the review of the relevant literature, this study applies the TVPSVAR model to econometrically examine the relationships between price stability (measured as the difference of inflation rates in the US from their mean) and financial stability (measured in the form of an index that encapsulates different financial indicators). Monthly data set for the period 1993:12-2020:12 is used. Within the scope of the study, there is an objective to econometrically determine which of the traditional wisdom and/or new environment hypotheses best explain, concerning time, the changing nature of the relationship between price and financial stability represented by more direct and inclusive variables in the context of the US. The findings of the study are thought to contribute to the emerging empirical literature after the GFC and largely support the new environment hypothesis by examining the variables used to represent price and financial stability using econometric methods that take into account nonlinearity in variables and the time-varying relationships between price and financial stability.

\section{ECONOMETRIC METHODOLOGY AND DATA}

In this part of the paper, explanations of the econometric methodology used in the study, which aims to empirically examine the time-varying nature of the relationship between price and financial stability in the US as well as the data set, are presented. The structure of the TVP-SVAR model based on time series analysis methodology and the nature and sources of data used in the study are explained in the following subsections.

\subsection{Time-varying parameter structural vector autoregression model (TVP-SVAR)}

The TVP-SVAR model was introduced by Primiceri (2005) by extending the linear vector autoregression (VAR) and structural vector autoregression (SVAR) models developed by Sims (1986) and Shapiro \& Watson (1988). The TVP-SVAR model involves eliminating variabilities in parameters following the determined order of the endogenous variables in the VAR and SVAR models. TVP-SVAR models also relax the assumptions that the parameters and structural shocks follow a linear process. In a TVP-SVAR model, following the determined order of endogenous variables, parameters and structural shocks do not change; however, they can follow a linear or nonlinear process, and the time-varying effects of the parameters of the endogenous variables as well as structural shocks are examined. In a TVP-SVAR model where the parameters of the endogenous variables and the variance-covariance matrix are allowed to 
change over time, time-dependent changes and nonlinear trends are likely to occur in the lag structure of the variables (Dahem et al., 2017).

A TVP-SVAR model that is based on a time series analysis methodology with a stochastic volatility model makes it possible to capture linear and nonlinear trends in the simultaneous relationships between endogenous variables and to eliminate problems associated with the varying variance in the time structure of structural shocks (Primiceri, 2005). In the TVP-SVAR model, the time-varying relationships between endogenous variables are assumed to follow a first-order random walk process and are investigated with the following regression equation:

$$
\mathrm{Y}_{\mathrm{t}}=\mathrm{c}_{\mathrm{t}}+\beta_{1 \mathrm{t}} \mathrm{y}_{\mathrm{t}-1}+\ldots+\beta_{\mathrm{st}} \mathrm{y}_{\mathrm{t}-\mathrm{s}}+\mathrm{e}_{\mathrm{t}}, \quad \mathrm{e}_{\mathrm{t}} \sim \mathrm{N}\left(0, \Omega_{\mathrm{t}}\right)
$$

Here, the terms $Y_{t}$ and $c_{t}$ indicate the endogenous variables and constant term vector in a $k \times 1$ dimension. The terms $\beta_{i t}$ and $\Omega_{t}$ indicate the variancecovariance matrix of coefficients and residuals that varies over time in the $(k \times k)$ dimension. The recursive identification $\Omega_{t}$ term for structural shocks can be differentiated as follows:

$$
\Omega_{t}=A_{t}^{-1} \sum_{t} \sum_{t}^{\prime}\left(A_{t}^{-1}\right)^{\prime}
$$

The $\Sigma_{t}$ and $A_{t}$ terms in the equation show the diagonal matrix of the timevarying components of the structural shocks in the endogenous variables. The lower triangular matrix of the covariance components that enables the determination of the time-varying relationships between the endogenous variables can be specified as follows:

$$
\sum_{t}=\left(\begin{array}{cccc}
\sigma_{1} & 0 & \ldots & 0 \\
0 & \ddots & \ddots & \vdots \\
\vdots & \ddots & \ddots & 0 \\
0 & \ldots & 0 & \sigma_{k}
\end{array}\right), A_{t}=\left(\begin{array}{cccc}
1 & 0 & \ldots & 0 \\
\alpha_{21, t} & \ddots & \ddots & \vdots \\
\vdots & \ddots & \ddots & 0 \\
\alpha_{k 1, t} & \ldots & \alpha_{k, k-1, t} & 1
\end{array}\right)
$$

After this transformation process, the equation for the TVP-SVAR model in Equation 1 can be rewritten as follows:

$$
y_{t}=X_{1} \beta_{t}+A_{t}^{-1} \sum_{t} \varepsilon_{t}, \quad \varepsilon_{t}=\sim N(0, I)
$$

Here, $t=s+1, \ldots, n$ is a representation of the process of modeling varying parameters as specified by Primiceri (2005). However, in the lower triangular matrix, the clustered vector representation of the elements in the form of $\alpha_{t}=\left(\alpha_{21}, \alpha_{31}, \alpha_{32}, \ldots, \alpha_{k, k-1}\right)^{\prime}$ is used. In this notation, the variance-covariance 
matrix of the time-varying residuals is $h_{t}=\left(h_{1 t}, \ldots, h_{k t}\right)^{\prime}$ and $h_{j t}=\log \sigma_{j t}^{2}$, $(j=1, \ldots, k)$, while the parameters in the equation do not strictly have to follow a stationary process of $\mathrm{AR}(1)$ but a random walk process. Under these assumptions, the structure of the $\beta_{t}, \alpha_{t}$ and $h_{t}$ parameters can be defined as follows:

$$
\begin{aligned}
& \beta_{t+1}=\beta_{t}+\mu_{\beta t}, \\
& \alpha_{t+1}=\alpha_{t}+\mu_{\alpha t}, \\
& h_{t+1}=h_{t}+\mu_{h t},
\end{aligned} \quad\left(\begin{array}{c}
\varepsilon_{t} \\
\mu_{\beta t} \\
\mu_{\alpha t} \\
\mu_{h t}
\end{array}\right) \sim N\left(0,\left(\begin{array}{cccc}
1 & 0 & 0 & 0 \\
0 & \sum_{\beta} & 0 & 0 \\
0 & 0 & \sum_{\alpha} & 0 \\
0 & 0 & 0 & \sum_{h}
\end{array}\right)\right)
$$

Here, when $t=s+1, \ldots, n$, the parameters $\beta_{s+1} \sim N\left(\mu_{\beta 0}, \sum_{\beta 0}\right)$, $\alpha_{s+1} \sim N\left(\mu_{\alpha 0}, \sum_{\alpha 0}\right)$ and $h_{s+1} \sim N\left(\mu_{h 0}, \sum_{h 0}\right)$ are normally distributed. The term $\varepsilon_{t}$ in the equations represents the elements of the diagonal matrix corresponding to the covariance matrix of structural changes. Here, $\mu_{\beta t}$ shows the lag coefficients, $\mu_{\alpha t}$ shows the simultaneous coefficients, and $\mu_{h t}$ shows the time-varying structural changes in the standard errors. The transformation of $\left(A_{t}\right)$ in Equation 4 into a lower-triangular matrix transforms the VAR system into a recursive definition, rendering the estimation of the models in the SVAR structure easier. To predict the TVP-SVAR model in Equation 4, the structural shocks derived from the variance-covariance matrix of the residuals from the reduced-form equation should be determined. Then, restrictions imposed on the covariance matrix, $\varepsilon_{t}$, of the structural shocks in the A matrix are defined in Equation 5. In the TVP-SVAR model as specified in Equation 4, the optimal lag length that eliminates autocorrelation in the residuals and the order of the endogenous variables in matrix A should be determined. The model is then estimated with the Markov Chain Monte Carlo (MCMC) method based on the random walk process and the Bayesian algorithm (Nakajima, 2011).

\subsection{Dataset}

The study uses monthly data obtained from the Federal Reserve Bank of St Louis FED (FRED Economic Data) database for the period 1993:12-2020:12. Data obtained from the FRED database and curated into a financial stability index to represent the financial stability (instability) level of the US for the study period 1993:12-2020:12 with regard to the scope of the study. The study considers four basic variables. The policy interest rate and the money supply variables that direct the relationship between price and financial stability through price stability, the financial stability and the monetary transfer mechanism constitute the basic variables for this study. Data on financial stability, policy interest rate and money supply variables are obtained directly from the FRED database. Data 
on the price stability variable, however, were curated by the authors using the actual inflation rate data obtained from the FRED database.

The financial stability (instability) variable symbolized as FS is drawn from the STLFSI2 Index (St. Louis Fed Financial Stress Index) values. This index captures the level of stability (stress) in the US financial markets calculated from different financial indicators contained in the FRED database. STLFSI2 was calculated using principal component analysis (PCA). This index accounts for the statistically explanatory degree of the combined movements of 18 financial indicators that directly, and from diverse perspectives, reflect the stability (stress) level of financial markets. The STLFSI2 index is designed and calculated to move weekly around a mean of zero since 1993:12. Values below 0 indicate a decreased level of stress and instability in financial markets, and values above 0 indicate increments in the level of stress and instability in financial markets. For comprehensive information on the scope and methodology of the STLFSI2 index, see (St. Louis Fed Financial Stress Index). The data on the policy interest rate variable, symbolized as FF in the study model, were obtained as the values of the Federal Reserve Bank's (FED) Effective Federal Funds Rate policy interest rate in percentages from the FRED database. The data on the money supply variable, symbolized as MS, were taken as seasonally adjusted billions of dollars (M2 money stock) values from the FRED database.

Data on the price stability variable, symbolized as PS in the study model, were derived by the authors based on the actual inflation rate data obtained from the FRED database and the average inflation rate within the $2 \%$ band used by the FED as a measure in defining the price stability. (The criterion used by FED to measure the annual inflation rate for the US on the consumer price index (CPI) within the limit of $2 \%$ is defined as price stability (FED, www. federalreserve.gov 2020). Inflation rate data from the FRED database calculated as seasonally adjusted monthly percentage change values based on the CPI $(2015=100)$ compared to the same month of the previous year were used to represent actual inflation rate data. In deriving the PS variable, the criterion that the annual average inflation rate should be within a limit of $2 \%$ pegged by the FED in measuring the price stability was used. Consequently, a new variable that consists of the average (potential) values of the inflation rate within a $2 \%$ band in the entire period was created. Then, the values of the average inflation rate variable created for the period 1993:12-2020:12 for the US were subtracted from the values of the actual inflation rate variable (taking its differences from the mean) for the period 1993:12-2020:12 to obtain the PS variable. Accounting for the uncertainty problems that arise from innovations and trends of filterbased methods such as Hodrick-Prescott, Kalman, and so on, which are used to calculate potential data under certain assumptions based on observed data, the average inflation rate was represented in the study with the FED's average inflation rates of $2 \%$ per year, used as a measure of the price stability in the US (Orphanides \& Norden, 2002; Hamilton, 2017).

In the econometric analysis, annual growth rate values (calculated following previous years' same month values) of MS and PS variables were seasonally 
adjusted from the relevant database. However, FS and FF variables are not periodically adjusted because they do not have seasonal characteristics. After the data transformation process, descriptive statistics on the FS, FF, MS and PS variables included in the econometric analysis for the period 1993:12-2020:12 are obtained and presented in Table 1.

TABLE 1

DESCRIPTIVE STATISTICS

\begin{tabular}{|lccccccccc|}
\hline Statistics & Mean & Median & Maximum & Minimum & Std. Dev. & Skewness & Kurtosis & $\begin{array}{c}\text { Jarque- } \\
\text { Bera }\end{array}$ \\
\hline PS & 0.188 & 0.207 & 3.498 & -3.958 & 1.124 & -0.407 & 4.101 & 25.39 \\
FS & -62.05 & -30.93 & 6469.6 & -5655.4 & 719.1 & 0.011 & 41.82 & 20415.2 \\
FF & 18.30 & 4.962 & 245.4 & -97.93 & 73.26 & 0.877 & 3.593 & 46.45 \\
MS & 6.284 & 5.993 & 25.99 & 0.316 & 3.540 & 2.948 & 16.15 & 2814.2 \\
\hline Observations & 325 & 325 & 325 & 325 & 325 & 325 & 325 & 325 \\
\hline
\end{tabular}

As seen in Table 1, the variables are ranked as FS, FF, MS and PS from largest to smallest in terms of the differences between the mean and median and the maximum and minimum statistical values and, therefore, the size of the standard deviation (Std. Dev.) statistical values. These findings show that the variables were ranked as FS, FF, MS and PS in terms of the magnitude of the changes they were exposed to during the study period and their differences from the mean values. However, the findings reveal that the changes in the FS and FF variables during the study period are much greater than the changes in the MS and PS variables. As shown in Table 1, the skewness, kurtosis and Jarque-Bera statistics of the PS, FS, FF and MS variables differ significantly from 0 . This finding shows that the PS, FS, FF, and MS variables were relatively skewed and flattened distributions during the study period, which reveals that they did not exhibit a normal distribution.

\section{EMPIRICAL FINDINGS}

In this section, the relationship between price and financial stability in the US is examined empirically with the TVP-SVAR model within the scope of time series analysis methodology for the period 1993:12-2020:12. To this effect, the price stability (PS), financial stability (FS), policy interest rate (FF) and money supply (MS) variables in the study on the monetary policy designs of the US are declared endogenous. The variables are included in matrix A of the TVP-SVAR model as defined earlier in Equation 4, as PS, FS, FF and MS in respective order. The TVP-SVAR model equation defined to determine the time-varying effects of the relationships between PS, FS, FF and MS in the US 
is estimated for the period 1993:12-2020:12. In determining the endogenous variables in the TVP-SVAR model and their subsequent rankings in matrix A, references were drawn from studies by Granville \& Mallick (2009), Blot et al., (2015) and Sethi \& Acharya (2020) in the relevant empirical literature on the subject matter. (Winrats 10.0, Gauss 16.0 and OxMetrics 7.0 econometrics software packages were used in the analysis of the study data).

According to Çatık (2020), it is necessary to determine the movements (linear and nonlinear structures) of the variables included in the established TVPSVAR model before proceeding with estimations (Çatık, 2020). Determining the linear structure of the variables in the model guides the econometric methodology and helps to obtain test statistics and results that are unbiased (Hoque and Zaidi, 2019: 996). To circumvent the aforementioned drawbacks of the study, the linear structure of the movements of the variables in the TVP-SVAR model over the analysis period is examined with linearity tests of Harvey \& Leybourne (2007-HL) and Harvey et al. (2008-HR). The HL and HR linearity tests, as documented in the time series literature, can be used when variables are stationary or not at level values and, in any case, give consistent results. In the HL test, the linearity of the variables is examined with the Wald, $W_{T}^{*}$, type test statistics and in the HR test with the Wald, $W_{S}, W_{U}$ and, $W_{\lambda}$ type test statistics. If the Wald test statistics obtained in the HL and HR tests are greater than the critical values, the null hypothesis that "the variables are linear" is rejected, and then, a conclusion that the variables exhibit nonlinear trends during the period under review is arrived at (Harvey \& Leybourne, 2007; Harvey et al., 2008). (For comprehensive information on the methodology of these tests, see Harvey \& Leybourne, 2007; Harvey et al., 2008). HL and HR test results on the linear structure of the variables in the TVP-SVAR model are presented in Table 2.

TABLE 2

TEST OF LINEARITY RESULTS

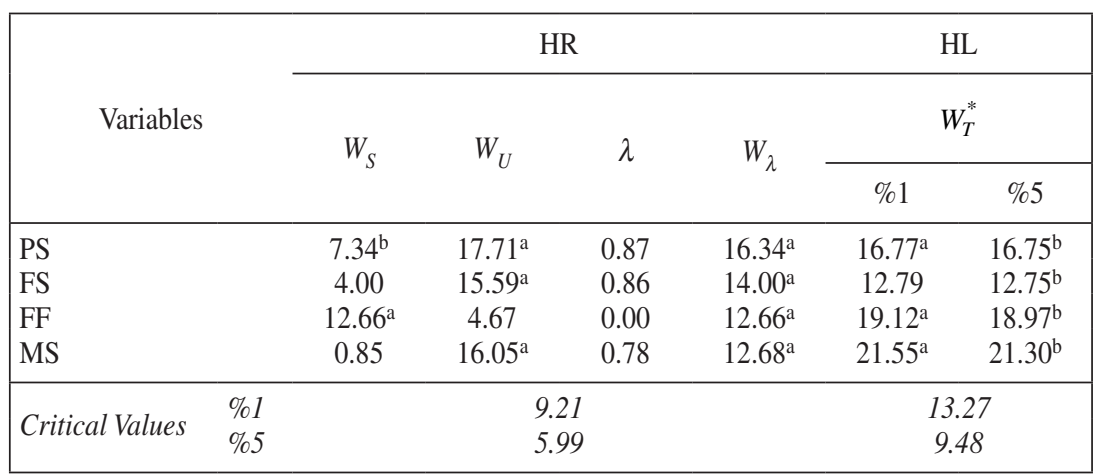

Note: The "a" and "b" signs in front of the test statistics calculated with $\left(\chi^{2}=2\right)$ degrees of freedom indicate that the null hypotheses are rejected at the $1 \%$ and $5 \%$ significance levels, respectively. The term " $\lambda$ " in the table indicates the weights of the $W_{S}$ and $W_{U}$ test statistics in the calculation of the $W_{\lambda}$ test statistics. 
The test results in Table 2 indicate that all variables are nonlinear at the $1 \%$ or 5\% significance level following HR and HL test results. This conclusion is reached by rejecting the linearity null hypotheses since the Wald test statistics calculated for PS, FS, FF and MS variables are greater than the critical values at the $1 \%$ or $5 \%$ significance level. Since the PS, FS, FF and MS variables in the TVP-SVAR model exhibit a nonlinear distribution during the review period, it is necessary for the degree of stationarity of the variables to be investigated with unit root tests that account for nonlinearity (Cuestas \& Garrant, 2011). Accordingly, the stationarity status of the variables in the TVP-SVAR model, symmetric and asymmetric properties of variables, deterministic and stochastic structure, etc., were considered, and Kapetanios et al. (2003-KSS) and Sollis (2009-SLS) unit root tests that incorporate nonlinear characteristics of the variables were used.

KSS unit root tests developed by Kapetanios et al. (2003) and SLS unit root tests by Sollis (2009) can be used in stationarity analysis when time-series data are nonlinearly distributed. However, the KSS and SLS unit root tests perform well under a set of assumptions when variables exhibit symmetric or asymmetric properties. The stationarity of nonlinear time series data is examined with an exponential and smooth transition autoregressive process in the KSS unit root test and an exponential or logistically smooth transition autoregressive process in the SLS unit root test. In KSS and SLS unit root tests, the stationarity of variables is examined using the demeaned (demeaned-D) and demeaned and detrended-DD forms. The null hypothesis that "there is a unit root in the series" is tested. If the KSS and SLS test statistics are greater than the absolute critical values, the null hypotheses are rejected, and the variables are said to be stationary over the review period (Kapetanios et al., 2003; Sollis, 2009). For comprehensive information on the methodology of these tests, see Kapetanios et al. (2003) and Sollis (2009). The KSS and SLS unit root test results in the TVP-SVAR model in the form of DD are presented in Table 3.

TABLE 3

KSS AND SLS UNIT ROOT TEST RESULTS

\begin{tabular}{|lccccc|}
\hline \multicolumn{2}{|c}{ Test Statistics } & \multicolumn{2}{c}{ KSS } & \multicolumn{2}{c|}{ SLS } \\
\hline \multicolumn{2}{|c}{ Variables } & DD & L & DD & L \\
\hline PS & $-3.46^{\mathrm{b}}$ & 4 & $6.97^{\mathrm{b}}$ & 4 \\
FS & & $-4.77^{\mathrm{a}}$ & 3 & $18.47^{\mathrm{a}}$ & 2 \\
FF & $-4.18^{\mathrm{a}}$ & 4 & $10.50^{\mathrm{a}}$ & 3 \\
MS & & $-3.45^{\mathrm{b}}$ & 2 & $8.20^{\mathrm{b}}$ & 2 \\
\hline Critical Values & $\% 1$ & & -3.93 & & 8.95 \\
& $\% 5$ & & -3.40 & & 6.59 \\
\hline
\end{tabular}

Note: The "a" and "b" signs in front of the test statistics indicate stationarity at the $1 \%$ and $5 \%$ significance levels, respectively. The optimal lag lengths determined for the variables based on the Akaike Information Criteria (AIC) are reported in column "L". Critical values for the KSS and SLS tests are taken from Kapetanios et al. (2003) and Sollis (2009), respectively. 
Table 3 shows that all variables are stationary at level values $[\mathrm{I}(0)]$ at the $1 \%$ or $5 \%$ significance level following KSS and SLS unit root tests. This conclusion was reached with both KSS and SLS unit root test statistics calculated at the $[\mathrm{I}(0)]$ level for PS, FS, FF and MS variables greater than the absolute value of the critical values and, consequently, rejecting the null hypotheses of a unit root. Since all variables considered in the study are declared stationary at level values, the TVP-SVAR model defined in Equation 4 is estimated using the level values of the PS, FS, FF and MS variables. The optimal lag length of the estimated TVP-SVAR model to examine the time-varying relationships between the variables included in matrix A with PS, FS, FF and MS is obtained as 3 with marginal likelihood (ML) and according to the highest ML value. The efficiency results of the Bayesian MCMC algorithm with 12,000 iterations and 2,000 joint posterior distributions of the time-varying parameters of the TVPSVAR (3) model estimated in the study are presented in Table 4.

TABLE 4

TVP-SVAR MODEL PARAMETER ESTIMATION RESULTS

\begin{tabular}{|lccccc|}
\hline Parameters & Mean & $\begin{array}{c}\text { Standard } \\
\text { Deviation }\end{array}$ & $\begin{array}{c}\text { Confidence } \\
\text { Intervals (\%95) }\end{array}$ & CD & IF \\
\hline$\left(\Sigma_{\beta}\right)_{1}$ & 0.0228 & 0.0025 & {$[0.0183-0.0284]$} & 0.936 & 26.61 \\
$\left(\Sigma_{\beta}\right)_{2}$ & 0.0181 & 0.0016 & {$[0.0153-0.0215]$} & 0.728 & 15.64 \\
$\left(\Sigma_{\alpha}\right)_{1}$ & 1.1498 & 1.1036 & {$[0.0950-0.1550]$} & 0.224 & 96.12 \\
$\left(\Sigma_{h}\right)_{1}$ & 1.1498 & 0.1036 & {$[0.9587-1.3605]$} & 0.125 & 92.21 \\
$\left(\Sigma_{h}\right)_{2}$ & 1.6593 & 0.1429 & {$[1.3976-1.9527]$} & 0.743 & 36.09 \\
\hline
\end{tabular}

From Table 4, the posterior distributions of the parameters in the TVP-SVAR (3) model converge, and the MCMC algorithm produces effective results. Thus, the null hypotheses stating that the posterior distributions of the parameters converge in the CD test (Geweke, 1992) were not rejected at the 5\% significance level, and the IF (inefficiency factors) values were relatively low (the number of repetitions was sufficient for the posterior distributions of the parameters to converge). However, in the TVP-SVAR (3) model presented in the table, the lowest and highest IF values are $15.64 \%$ with $\left(\Sigma_{\beta}\right)_{2}$ in the time-varying structural change parameter of the lag coefficients and $96.12 \%$ with $\left(\Sigma_{\alpha}\right)_{1}$ and simultaneous coefficients, respectively. The results of the TVP-SVAR (3) model of the parameters $\left(\Sigma_{\beta}\right)_{1},\left(\Sigma_{\beta}\right)_{2},\left(\Sigma_{\alpha}\right)_{1},\left(\Sigma_{h}\right)_{1}$ and $\left(\Sigma_{h}\right)_{2}$ on the efficiency of the MCMC algorithm are presented in Figure A1 in the Appendix section.

Graphs showing the course of innovation, stochastic volatilities and the timevarying simultaneous relationships between the PS, FS, FF and MS variables in the TVP-SVAR (3) model for the period 1993:12-2020:12 are presented in Figures A2, A3 and A4, respectively, in the Appendix section. From Figure 
A2, it can be observed that the transformed forms of the PS, FS, FF and MS variables in the model follow a fluctuating innovation trend during the period under review, and these trends became evident in the years before, during and after the GFC. An examination of Figure 3 reveals that the PS, FS, FF and MS variables are listed as PS, FS, FF and MS in terms of the magnitude of the stochastic volatilities (the mean values of the structural shocks) during the sampling period. Additionally, stochastic volatilities that show similar trends in the PS, FS, FF and MS variables increased significantly in the 1999, 2005, 2010 and 2017 periods. Figure 4 depicts that the simultaneous relationships between the PS, FS, FF and MS variables stemming from the structural shocks specified recursively differ, to a certain extent, according to the variables and time. In addition, Figure 4 also shows that the simultaneous relationship between the PS and FS variables for the period 1993-2020 is positive and has become relatively stronger since 2000 . This situation not only indicates that there were a priori simultaneous relationships between the PS and FS variables during the period review but also shows that the magnitude of these relationships changes over time. Moreover, Figure 4 also shows that similar findings are valid with regard to relationships between the PS, FS, FF and MS variable groups, albeit at different scales.

The results obtained from the analysis of the impulse-response functions that examine the time-varying relationships between the price stability, financial stability, policy interest rate and money supply in the US from the variancecovariance matrix of the parameters are presented in Figures 1, 2, 3 and 4. Figure 1 represents structural shocks caused by the price stability (PS), Figure 2 represents structural shocks originating from financial stability (FS), Figure 3 represents structural shocks originating from the policy interest rate (FF) variable, and Figure 4 shows structural shocks from the money supply (MS). The structural shocks from the money supply (MS) variable in Figure 4 depend on other time-varying variables and show the degree (direction/magnitude) of their responses according to term periods (1993-2020 period and short 1-month (1-M), mid-term 1-quarter (1-Q) and long-term 1-year (1-Y).

From Figure 1, it can be observed that the FS variable gives continuous positive responses to structural shocks in the PS at the 1-M, 1-Q and 1-Y terms (periods) during the period 1993-2020. Additionally, the magnitudes of these positive responses of the FS variable in the 1-Q and 1-Y terms (periods) were generally similar during the 1993-2020 period. However, the degree of positive responses increased in the period 2002-2009. These findings show that structural shocks in the PS increased the financial instability in the short, medium and long term over the entire study period. The effects that caused financial instability in the medium to long term became evident in the period 2002-2009. A thorough analysis of Figure 1 reveals that the FF variable gives continuous positive responses to structural shocks in PS at the 1-M and 1-Q terms during the 1993-2020 period; however, the degree of positive responses increased at the 1-Q term. The FF variable exhibits a positive response at $1-Y$ terms in the periods 1993-2004 and 2008-2009 and a negative response in the periods 
FIGURE 1

TVP-VAR MODEL: TIME-VARYING RESPONSE TO SHOCKS IN THE PRICE STABILITY
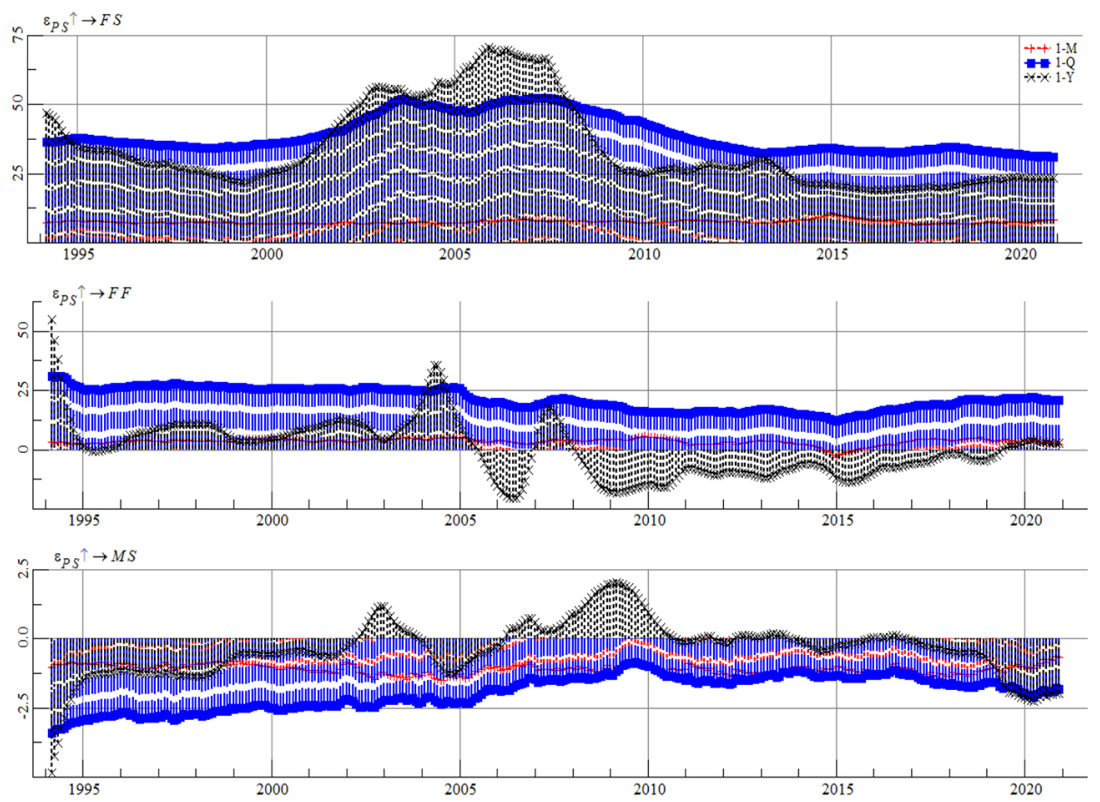

2005-2007 and 2010-2019. These findings show that structural shocks in PS increased policy interest rates in the short-medium term in the entire period 1993-2020. However, in the long term, there were increased policy rates in the periods 1993-2004 and 2008-2009 and decreased policy rates in the periods 2005-2007 and 2010-2019.

Moreover, in Figure 1, the MS variable exhibits continuous negative responses to structural shocks in PS at 1-M and 1-Q terms during the 1993-2020 period, with an increased degree of negative responses at 1-Q terms. The responses of the MS variable in 1-Y maturities are positive in the 2002-2004 and 2005-2016 periods and negative in the 1993-2001 and 2017-2020 periods. These findings show that structural shocks in PS decreased the money supply in the short-tomedium term throughout the 1993-2020 period. However, it increased in the long term in 2002-2004 and 2005-2016 and decreased in the periods 1993-2001 and 2017-2020.

In Figure 2, the responses of the PS variable to structural shocks in FS at the 1-M, 1-Q and 1-Y terms are negative in the 2000-2001, 2006-2010 and 2014-2016 periods and positive in the 1993-1999, 2002-2005, 2011-2013 and 2017-2019 periods. On the other hand, the magnitudes of the negative-positive responses of the PS variable in the 1-M, 1-Q and 1-Y terms are generally similar, and the largest negative and positive responses are observed in the periods 2007-2008 and 2004-2005, respectively. These findings indicate that structural 


\section{FIGURE 2}

TVP-VAR MODEL: TIME-VARYING RESPONSE TO SHOCKS IN FINANCIAL STABILITY
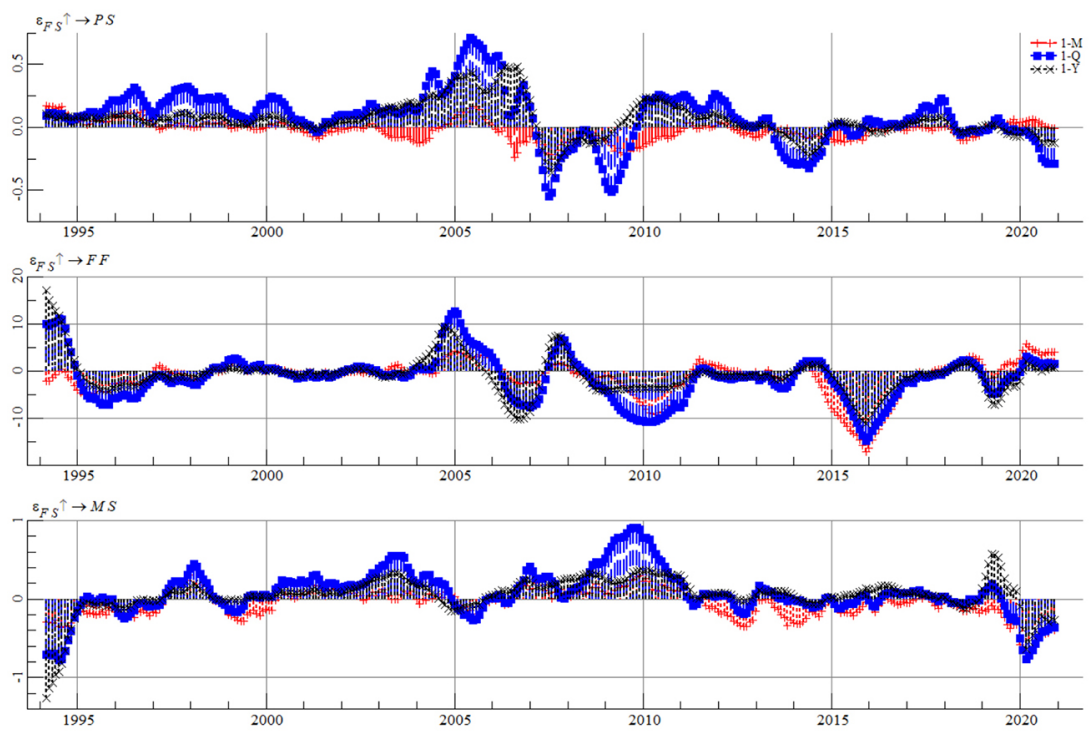

shocks in FS contribute to price stability in the short-, medium- and long-term periods 2000-2001, 2006-2010, and 2014-2016 and especially 2007-2008, 1993-1999, 2002-2005, 2011-2013, and 2017-2019. The results also show that structural shocks in FS caused price instability, especially in the 2004-2005 period. Figure 2 shows that the FF variable exhibits similar positive or negative responses to structural shocks in FS at the 1-M, 1-Q and 1-Y terms during the 1993-2020 period, and the degree of these reactions increased significantly after 2005. However, the FF variable gives the greatest positive and negative responses for the 1-M, 1-Q and 1-Y terms in the periods 2005-2008 and 20152016. These outcomes show that structural shocks in FS have had an impact on policy rates in the short, medium and long term during the 1993-2020 period. Notably, policy rates increased in the period of 2005-2008 and decreased in the 2015-2016 period. Figure 2 shows that the responses of the MS variable to structural shocks in FS at the 1-M, 1-Q and 1-Y terms are generally negative in the periods 1993-1997, 1999-2000, 2004-2006 and 2019-2020 and positive in the periods 2001-2003 and 2007-2018. Nevertheless, the MS variable exerts the greatest negative and positive responses in the 1-M, 1-Q and 1-Y terms in the periods 2019-2020 and 2008-2011. These findings demonstrate that structural shocks in FS decreased the money supply in the short, medium and long term in 1993-1997, 1999-2000, 2004-2006 and especially in the 2019-2020 period. An increment in the money supply was experienced in the periods 1998-20012003 and, especially, 2007-2018. 
FIGURE 3

TVP-VAR MODEL: TIME-VARYING RESPONSE TO SHOCKS IN THE POLICY INTEREST RATE
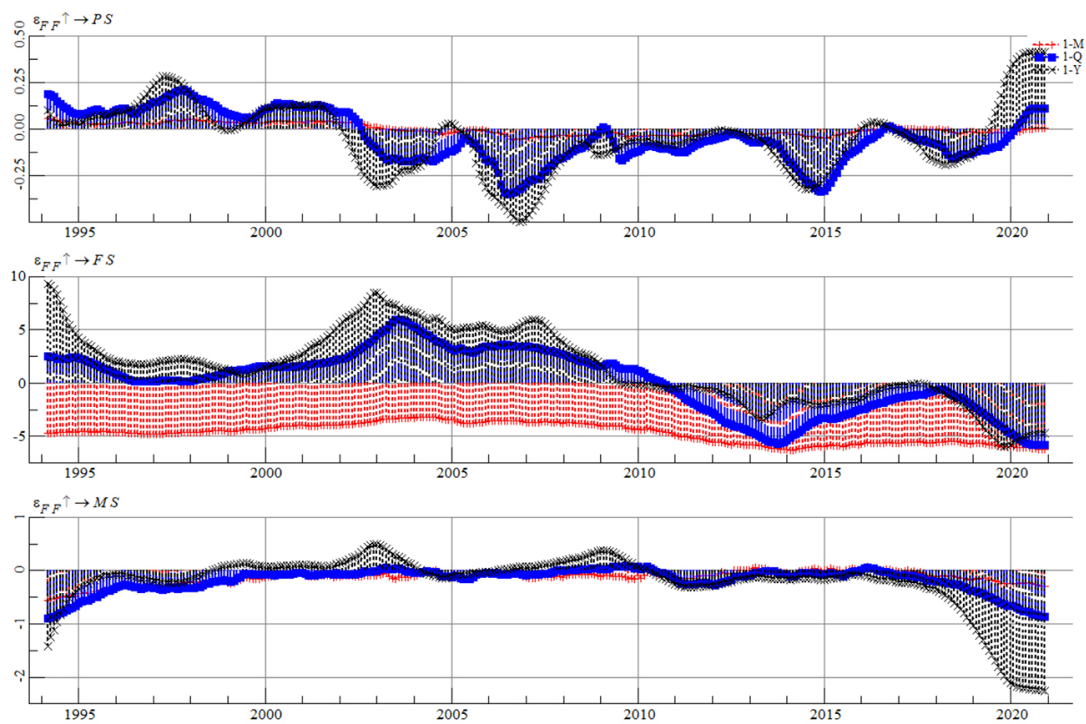

A careful examination of Figure 3 reveals that the responses of the PS variable to structural shocks in FF at the 1-M, 1-Q and 1-Y terms are generally negative in the 2003-2018 period and positive in the 1993-2002 and 2019-2020 periods. This figure also depicts that the PS variable exerts increasing, parallel from short term to long term, negative and positive reactions in the periods from 2005-2007 and 2001-2002. Even though structural shocks to the FF cause price instability in the short, medium and long term in 1993-2002, 2019-2020 and especially in the 2001-2002 periods, they contribute to price stability in 2003-2018 and especially in the period from 2005-2007. Additionally, it can be inferred from Figure 3 that the FS variable exerts negative responses in 1-M terms and positive or negative responses in 1-Q and 1-Y terms with a similar magnitude to structural shocks in FF during the 1993-2020 period. However, the FS variable exerts stronger negative and positive reactions with parallel increments from the short term to the long term in the 2013-2015 and 20042009 periods, respectively. These findings demonstrate that while the structural shocks to the FF variable caused financial instability in the short term during the 1993-2020 period, they contributed to financial stability in the medium-long term in the 1993-2011 period and thereafter increased financial instabilities in the 2012-2020 period. Moreover, Figure 3 shows a negative response by the MS variable to structural shocks in FF in the 1-M, 1-Q and 1-Y terms for the 1993-1999 and 2005-2007 periods and positive responses of similar magnitude in the 2000-2004 and 2008-2010 periods. Figure 3 posits that the money supply 
exhibits strong negative responses to structural shocks in FF in the 2019-2020 period and a negative response in 2009-2010. The results indicate that structural shocks FF decreased the money supply in the short, medium and long term in 1993-1999, 2005-2007 and especially in the 2019-2020 period but increased the money supply in 2000-2004, 2008-2010 and significantly in 2009-2010.

FIGURE 4

TVP-VAR MODEL: TIME-VARYING RESPONSE TO SHOCKS IN THE MONEY SUPPLY

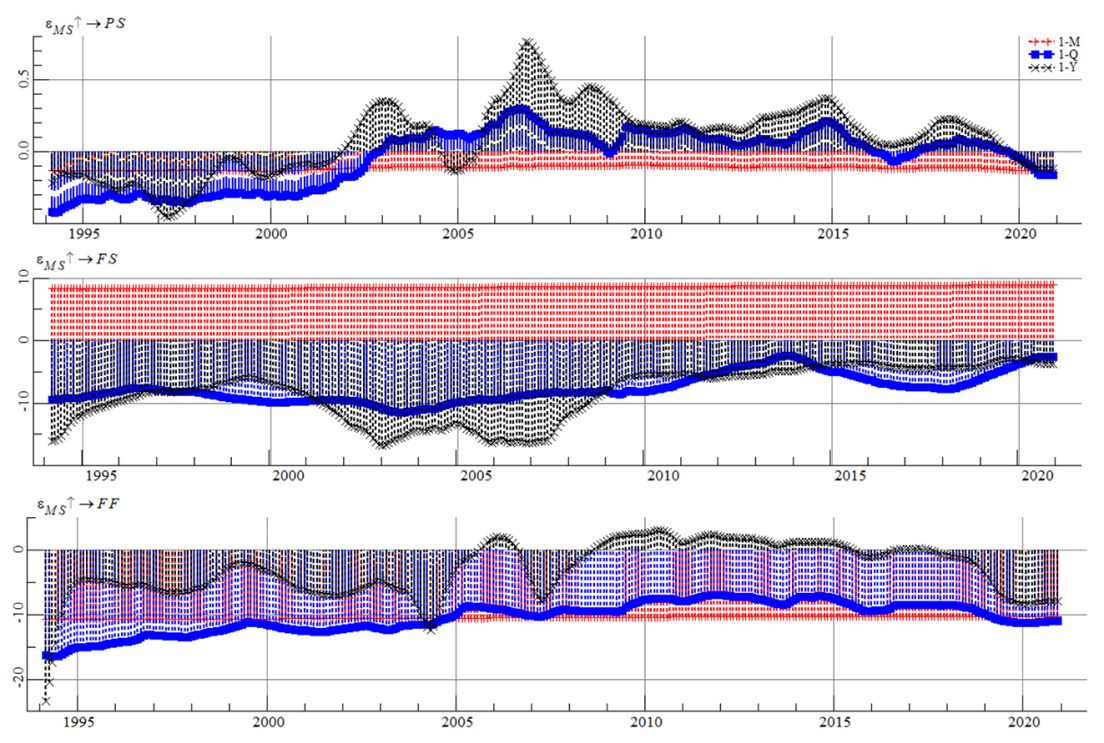

Figure 4 reveals that the PS variable exerts negative responses to structural shocks in MS for the 1-M term during the period 1993-2020 and positive or negative responses of similar magnitude in 1-Q and 1-Y terms. On the other hand, the PS variable gives strong negative and positive reactions that increase in a form directly parallel to the short term to long term in the periods 1993-2000 and 2005-2010, respectively. These outcomes indicate that structural shocks to MS contribute to price stability during the period under review. Notably, the price stability is observed in the short term and medium-long term in 1993-2003 and 2019-2020, and increments in the price instability are seen in the medium-long term in the period 2004-2018. Additionally, Figure 4 shows that the FS variable reacts positively to the 1-M term and negatively to the 1-Q and 1-Y terms during the period under review. However, the positive and negative reactions of the FS variable increased in a parallel form from the short term to the long term with stronger negative responses in the 2003-2010 period. These results show that structural shocks in MS caused short-term financial instability throughout the period under review but contributed to financial stability in the medium-long 
term, and this effect became evident in the period 2003-2010. The FF variable responds negatively to structural shocks in MS at the 1-M and 1-Q terms and positive or negative responses of similar magnitudes at the $1-\mathrm{Y}$ terms during the period under review. However, the FF variable exerts the strongest positive responses in 2004-2005 and 2009-2015 and negative reactions in 1993-1995 and 2004-2008 that increase in a form parallel to the short term to long term. These findings indicate that structural shocks sustained in MS decreased policy interest rates in the short-medium term during the study period and in the long term in 1993-1995 and 2004-2008. However, policy interest rates increased in the long term in the periods 2004-2005 and 2009-2015.

\section{Conclusions}

In this study, the relationship between price and financial stability of monetary policy designs is explained, and the relationship between price and financial stability in the US's monetary policy designs is examined by considering the propositions of traditional wisdom developed in the 1990s and the new environment hypotheses. To achieve this purpose, the time-varying nature of the relationship between the price stability, financial stability, policy interest rate and money supply in the US, where monetary policies are designed to achieve price stability, full employment and moderate long-term interest rate targets, is studied econometrically with the TVP-SVAR model for the period 1993:122020:12. The results of the estimated TVP-SVAR models are parallel with the empirical findings of studies by Dhal et al. (2011), Blot et al. (2015), Sethi \& Acharya (2020) and Sahoo (2020), who found mutual relationships between price and financial stability and who corroborate the proposition of the new environment hypothesis in the theoretical literature that price stability may not necessarily guarantee financial stability.

The output of the TVP-SVAR model estimated for this study reveals that the relationship between the price stability, financial stability, policy interest rate and money supply is mutual and varies significantly over time (short-, medium- and long-term periods in the years considered in the study) in the monetary policy designs of the US. Models established to investigate the relationship between the price and financial stability in the study show that price instabilities prevent financial stability by increasing the accumulation of systemic risk in financial markets in the short, medium and long term during the study period. Contrasting results were observed for certain periods and times in which financial instabilities supported or prevented the price stability by either decreasing or increasing the differences in the inflation rates from the mean in the sample period. Moreover, mixed results were obtained on the effects of price instabilities in preventing financial stability in the period of 2002-2009. Financial instabilities were found to prevent price stability in the period 2004-2005, and supportive effects of financial instabilities on price stability were noticed in the period 2007-2008. The theoretical background of these results, which reveals that price stability 
might not guarantee financial stability and could even feed financial instability in certain periods or conditions, is in line with the study of Leijonhufvud (2007). In fact, in the study of Leijonhufvud (2007), price stability can prevent financial stability by increasing the accumulation of systemic risk in financial markets in certain periods or conditions.

In TVP-SVAR models where the relationship between price stability and the policy interest rate is examined, it is found that price instabilities increase or decrease policy interest rates by tightening or loosening monetary policy stances. The results from such models also indicate that changes in policy rates support or prevent price stability by decreasing or increasing the differences in the inflation rates from the mean values in the sample period. The results from such models, notably, reveal the effects of price instabilities on increasing policy rates and evidence that variabilities in policy interest rates support price stability were found in the 2004-2008 period. In models that focused on examining the relationship between price stability and money supply, it is found that price instabilities during the sample period reduce or increase the money supply by altering the opportunity cost of holding cash. These variabilities in the money supply were found to support or prevent price stability by either reducing or increasing the differences in the inflation rates from the mean values. Notably, the effects of price instabilities on reducing the money supply and, consequently, hindering price stability became evident in the 2004-2010 period.

In the models in which the relationship between financial stability and the policy interest rate is investigated, the results indicate that during certain periods and terms, financial instabilities increase or decrease policy interest rates, thereby resulting in a tighter or loosened monetary policy stance. Changes in policy rates were found to support or inhibit financial stability by either decreasing or increasing the accumulation of systemic risk in financial markets. Additionally, such models show that financial instabilities increase policy interest rates, and the reverse effects of variabilities in policy rates on financial stability were observed in the period 2004-2009. The study results also reveal certain periods and terms in the sample period where financial instability reduced or increased the money supply by changing the opportunity cost of holding money. Such changes in the money supply support or prevent financial stability by reducing or increasing the accumulation of systemic risk in financial markets. This finding became evident in the period 2004-2010. TVP-SVAR models established to examine the relationship between the money supply and policy interest rate show that changes in the money supply during the sample period increase or decrease policy interest rates through tight or loose monetary policies. Changes in the money supply were found to result in decreases in the policy interest rate in the period 1993-2000. The reverse effect indicates that changes in the policy interest rate decrease or increase the money supply by changing the opportunity cost of holding money. This effect became evident in the period 2016-2020.

These results show the bidirectional relationship between price stability, financial stability, policy interest rate and money supply in the US and changes over time in the periods before, during and after the 2008 global financial crisis. 
The time factor is important in the relationship between these variables. These results show that the reciprocal relationship between the price stability, financial stability, policy interest rate and money supply can change symmetrically and asymmetrically over time. Thus, it broadly suggests that policy interest rates that ensure price and financial stability might not always be compatible and that price stability might not always guarantee financial stability. In fact, the results of the study show that changes in the policy interest rate and/or money supply can provide price stability in certain periods and/or prevent financial stability by feeding systemic risks in financial markets. These results, which are theoretically compatible with the new environment hypothesis, show that it is necessary to regulate price stability, policy interest rate and money supply changes with a simultaneous approach that can prevent the accumulation of systemic risks in financial markets. In this context, as suggested in the studies of Borio \& Lowe (2002), Rajan (2005) and Leijonhufvud (2007), in the design of monetary policies, in regulating the relations between price stability, financial stability, policy interest rate and money supply, there are expectations, risk factors, which are financial systemic risk factors. It is necessary to consider the effects of changes in the credit market appetite and loan asset prices together. Nevertheless, these results point to emphasizing the need to design monetary policies with consideration of the time factor in the symmetrical and asymmetrical bidirectional relations between price stability, financial stability, policy interest rate and money supply. Based on these findings, monetary policies in the US must be redesigned within the framework of the new environment hypothesis with considerations to the changing nature of the relationship between monetary and financial variables over time. To this effect, US monetary policies implemented by the FED to achieve price stability, full employment and moderate long-term interest rate targets should be designed with substantial depth in their scope and purpose, to reduce the trade-offs between monetary and financial stability. The approach should incorporate a variety of tools that can direct the timing of the relationship between monetary and financial variables. In doing so, it will be possible to reduce the trade-offs between monetary and financial stability, regulate the relationship that varies symmetrically or asymmetrically over time between these variables, and ensure that financial stability and price stability support each other over time. Otherwise, the reciprocal relationship between monetary and financial stability is likely to be bound to certain conditions and periods, as depicted by study findings. Thus, financial instabilities will continue to threaten monetary stability and the output gap, as observed in the 2008 global financial crisis. In this study, it is evaluated that these results and policy implications for the explanation of the relations between monetary and financial stability in the monetary policy designs of the US could be valid to a certain extent in terms of the monetary policy designs of a significant part of developed and developing countries. In fact, after the 2008 global financial crisis, monetary policies were redesigned by a significant part of developed and developing countries with an understanding that aims to support monetary stability with financial stability, either explicitly or implicitly. Future empirical studies in line with the subject 
matter can examine the linear and nonlinear distributions of price and financial stability variables during the period under review within the context of different developed and developing countries to contribute to the development of the emerging empirical literature following the 2008 global financial crisis.

\section{REFERENCES}

Billi, R.M. and A. Verdin (2014). "Monetary Policy and Financial Stability-a Simple Story", Sveriges Riksbank Economic Review, Vol. 2; 7-22.

Blot, C., J. Creel, P. Hubert, F. Labondance, and F. Saraceno (2015). “Assessing the Link between Price and Financial Stability", Journal of Financial Stability, Vol. 16; 71-88.

Bordo, M.D. and D.C. Wheelock (1998). "Price Stability and Financial Stability: The Historical Record", Review, Federal Reserve Bank of St Louis, September/October, 41-62.

Bordo, M.D., M.J. Dueker, and D.C. Wheelock (2002). “Aggregate Price Shocks and Financial Instability: A Historical Analysis", Economic Inquiry, Vol. $40(4) ; 521-538$.

Borio, C. (2014a). "The Financial Cycle and Macroeconomics: What Have We Learnt?" Journal of Banking \& Finance, Vol. 45; 182-198.

Borio, C., (2014b). "Monetary Policy and Financial Stability: What Role in Prevention and Recovery?" Working Paper, No. 440. The Bank for International Settlements.

Borio, C., B. English, and A. Filardo (2003). "A Tale of Two Perspectives: Old or New Challenges for Monetary Policy”. Working Paper, No. 127. The Bank for International Settlements.

Borio, C. and P. Lowe (2002). "Asset Prices, Financial and Monetary Stability: Exploring the Nexus”, Working Paper, No. 114. The Bank for International Settlements.

Crockett, A. (1997). "Why is Financial Stability a Goal of Public Policy?", Economic Review, Federal Reserve Bank of Kansas City, Vol. 82 (4); 5-22.

Cuestas J.C. and D. Garrant (2011). "Is Real GDP Per Capita a Stationary Process? Smooth Transitions, Nonlinear Trends and Unit Root Testing”, Empirical Economics, Vol. 41; 555-563.

Çatık, A.N. (2020). "Electricity, Fossil Fuel Prices and Exchange Rate in Turkey". Romanian Journal of Economic Forecasting, Vol. 23 (3); 60-77.

Dahem, A., S. Skander, and S.G. Fatma (2017). "Time-Varying VAR Analysis for Disaggregated Exchange Rate Pass-through in Tunisia". Working Paper, No. 79759. Munich Personal RePEc Archive.

Demirguc-Kunt, A. and E. Detragiache (1998). "The Determinants of Banking Crises in Developing and Developed Countries", Working Paper, No. 45, IMF Staff Papers.

Dhal, S., P. Kumar, and J. Ansari (2011). "Financial Stability, Economic Growth, Inflation and Monetary Policy Linkages in India: An Empirical Reflection", Reserve Bank of India Occasional Papers, Vol. 32 (3); 1-35. 
Fouejieu, A. (2017). "Inflation Targeting and Financial Stability in Emerging Markets", Economic Modelling, Vol. 60; 51-70.

Fouejieu, A., A. Popescu, A., and P. Villieu (2019). "Trade-Offs Between Macroeconomic and Financial Stability Objectives", Economic Modelling, Vol. 81; 621-639.

Frappa, S. and J.S. Mésonnier (2010). "The Housing Price Boom of the Late 1990s: Did Inflation Targeting Matter?”, Journal of Financial Stability, Vol. 6 (4); 243-254.

Gadanecz, B. and K. Jayaram (2008). "Measures of Financial Stability-A review", Irving Fisher Committee Bulletin, Vol. 31; 365-383.

Granville, B. and S. Mallick (2009). "Monetary and Financial Stability in The Euro Area: Pro-Cyclicality Versus Trade-Off", Journal of International Financial Markets, Institutions and Money, Vol. 19 (4); 662-674.

Hamilton, J. (2017). "Why You Should Never Use the Hodrick-Prescott Filter", Working Paper, No: 23429. National Bureau of Economic Research.

Hardy, D. and C. Pazarbasioglu, C. (1999). "Determinants and Leading Indicators of Banking Crises: Further Evidence”, IMF Staff Papers, No. 463. International Monetary Fund.

Harvey, D.I. and S.J. Leybourne (2007). "Testing for Time Series Linearity", Econometrics Journal, Vol. 10; 149-165.

Harvey, D.I., S.J. Leybourne, and B. Xiao (2008), "A Powerful Test for Linearity When the Order of Integration is Unknown", Studies in Nonlinear Dynamics \& Econometrics, Vol. 12 (3), 1-22.

Hoque, M.E. and M.A.S. Zaidi (2019). "The Impacts of Global Economic Policy Uncertainty On Stock Market Return in The Regime-Switching Environment: Evidence From Sectoral Perspectives", International Journal of Finance \& Economics, Vol. 24 (2); 991-1016.

IMF-BIS-FSB. (2009). "Report to G20 Finance Ministers and Governors: Guidance to Assess the Systemic Importance of Financial Institutions, Markets and Instruments: Initial Considerations", October 28, 2009, p., 1-29. http:// www.imf.org/external/np/g20/pdf/100109.pdf, (Accessed at 04.06.2021).

IMF (2020). "World Economic Outlook: A Long and Difficult Ascent", Washington, DC, October. 1-182.

Issing, O. (2003). "Monetary and Financial Stability: Is There a Trade-Off?"

Working Paper, No. 18. The Bank for International Settlements.

Kapetanios G., Y. Shin, and A. Snell (2003). "Testing for a Unit Root in the Nonlinear STAR Framework”, Journal of Econometrics, Vol. 112; 359-379.

Karanovic, G. and Karanovic, B. (2015). "Developing An Aggregate Index for Measuring Financial Stability in The Balkans". Procedia Economics and Finance, Vol. 33; 3-17.

Kim, S. and A. Mehrotra (2017). "Managing Price and Financial Stability Objectives in Inflation Targeting Economies in Asia and the Pacific", Journal of Financial Stability, Vol. 29; 106-116.

Leijonhufvud, A. (2007). "Monetary and Financial Stability", CEPR Policy Insight, Vol. 14; 1-25. 
Mishkin, F.S. (2011). "Monetary Policy Strategy: Lessons from the Crisis", Working Paper, No. w16755. National Bureau of Economic Research.

Nair, A.R. and B. Anand (2020). Monetary Policy and Financial Stability: Should Central Bank Lean Against the Wind?", Central Bank Review, Vol. 20; 133-142.

Nakajima, J. (2011). Time-Varying Parameter VAR Model with Stochastic Volatility: An Overview of the Methodology and Empirical Applications", Monetary and Economic Studies, Vol. 29; 107-142.

Orphanides, A., and S. van Norden (2002). "The Unreliability of Output Gap Estimates in Real-Time", The Review of Economics and Statistics, Vol. 84, 569-583.

Özatay, F. (2012). "An Exploration into New Monetary Policy”, Iktisat Isletme ve Finans, Vol. 27 (315); 51-75.

Primiceri, G.E. (2005). "Time Varying Structural Vector Autoregressions and Monetary Policy”, The Review of Economic Studies, Vol. 72 (3); 821-852. Rajan, R.G. (2005). "Has Financial Development Made the World Riskier?" Working paper, No. 11728. National Bureau of Economic Research

Ramesh Babu, T. and M. Venkateswarlu (2017). "Dynamics of Financial Stress and Economic Performance of India”, International Journal of Applied Business and Economic Research, Vol. 15 (5); 1-17.

Roldán-Peña, J., M. Torres-Ferro, and A. Torres García (2017). "Trade-Offs Between Inflation Targeting and Financial Stability Objectives: Drivers of Gains from Coordinating Monetary and Macroprudential Policies", Working paper, No. 2017-22. Banco de México Documentos de Investigación.

Sahoo, J. (2020). "Financial Stress Index, Growth and Price Stability In India:

Some Recent Evidence", Transnational Corporations Review, In Press, 1-15. doi:10.1080/19186444.2020.1768789

Schwartz, A.J. (1995). "Why Financial Stability Depends on Price Stability", Economic Affairs, Vol. 15, 21-25.

Sethi, D., and D. Acharya (2020). "Monetary Policy and Financial Stability: The Role of Inflation Targeting", Australian Economic Review, Vol. 53 (1); 50-75.

Smets, F. (2014). "Financial Stability and Monetary Policy: How Closely Interlinked?", The International Journal of Central Banking, Vol. 35, 263-300.

Sollis, R. (2009). "A Simple Unit Root Test Against Asymmetric STAR Nonlinearity with An Application to Real Exchange Rates in Nordic Countries", Economic Modelling, Vol. 26; 118-125.

Van Roye, B. (2011). "Financial Stress and Economic Activity in Germany and the Euro Area", Working Paper, No. 1743. Kiel Institute for the World Economy.

White, W.R. (2006). “Is price stability enough?”, Working Paper, No. 205. The Bank for International Settlements.

Woodford, M., (2012). "Inflation Targeting and Financial Stability", Working Paper, No. 17967. National Bureau of Economic Research. 


\section{APPENDix}

FIGURE A1

ESTIMATION RESULTS FOR THE TVP-SVAR MODEL PARAMETERS
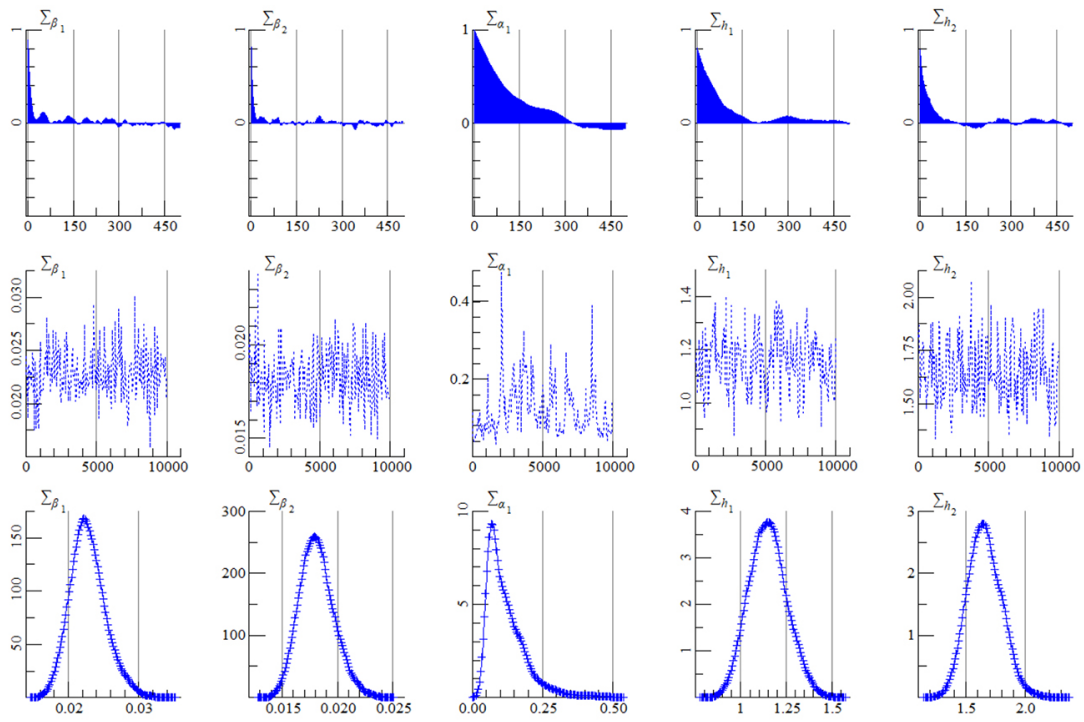

Note: The upper, middle and bottom parts of the graphs show sample autocorrelation, trends and successive densities of time-varying parameters in the TVP-SVAR (3) model, respectively.

\section{FIGURE A2}

TIME SERIES GRAPHS OF THE TVP-SVAR MODEL VARIABLES
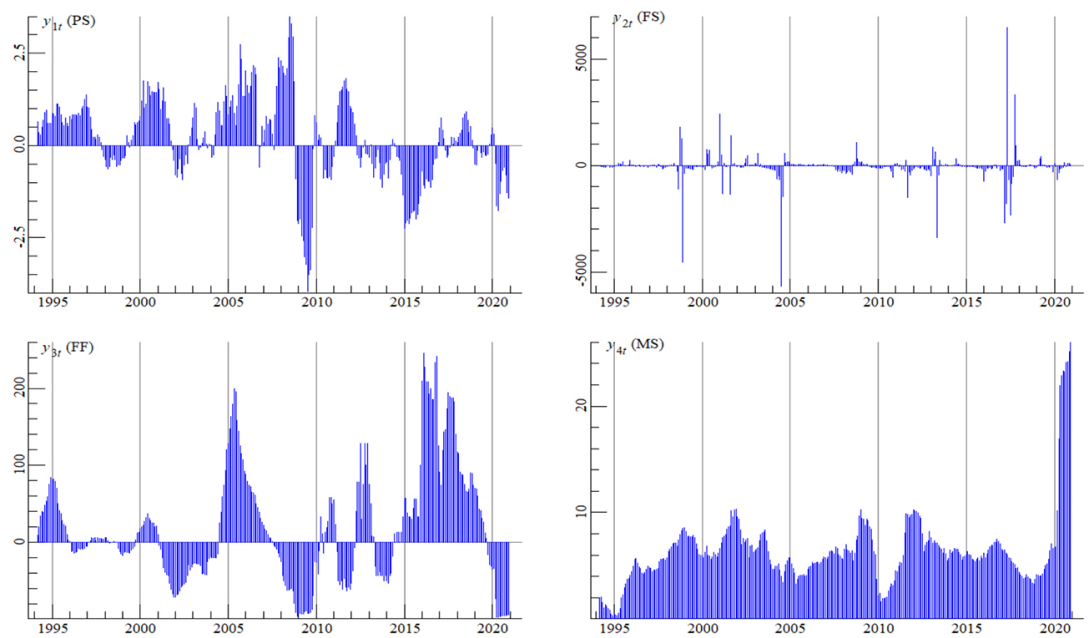
FIGURE A3

STOCHASTIC VOLATILITY OF THE VARIABLES IN THE TVP-SVAR MODEL
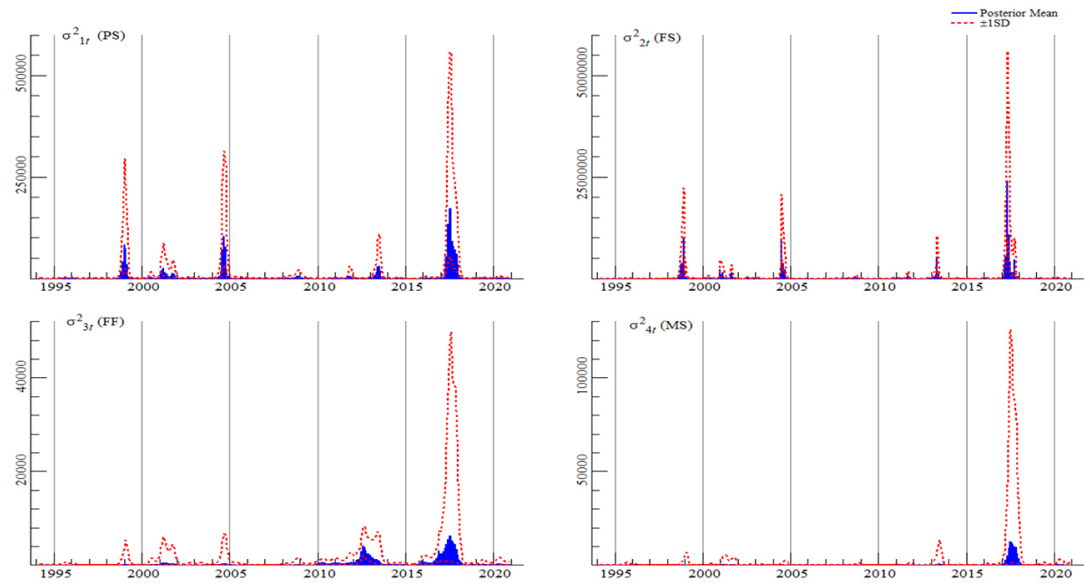

Note: The blue and continuous lines in the graphs indicate the successive means of the time-varying parameters in the TVP-SVAR (3) model, and the red and dashed lines indicate plus/minus standard deviations at a $99 \%$ confidence interval.

\section{FIGURE A4}

SIMULTANEOUS RELATIONSHIPS BETWEEN VARIABLES IN THE TVP-SVAR MODEL
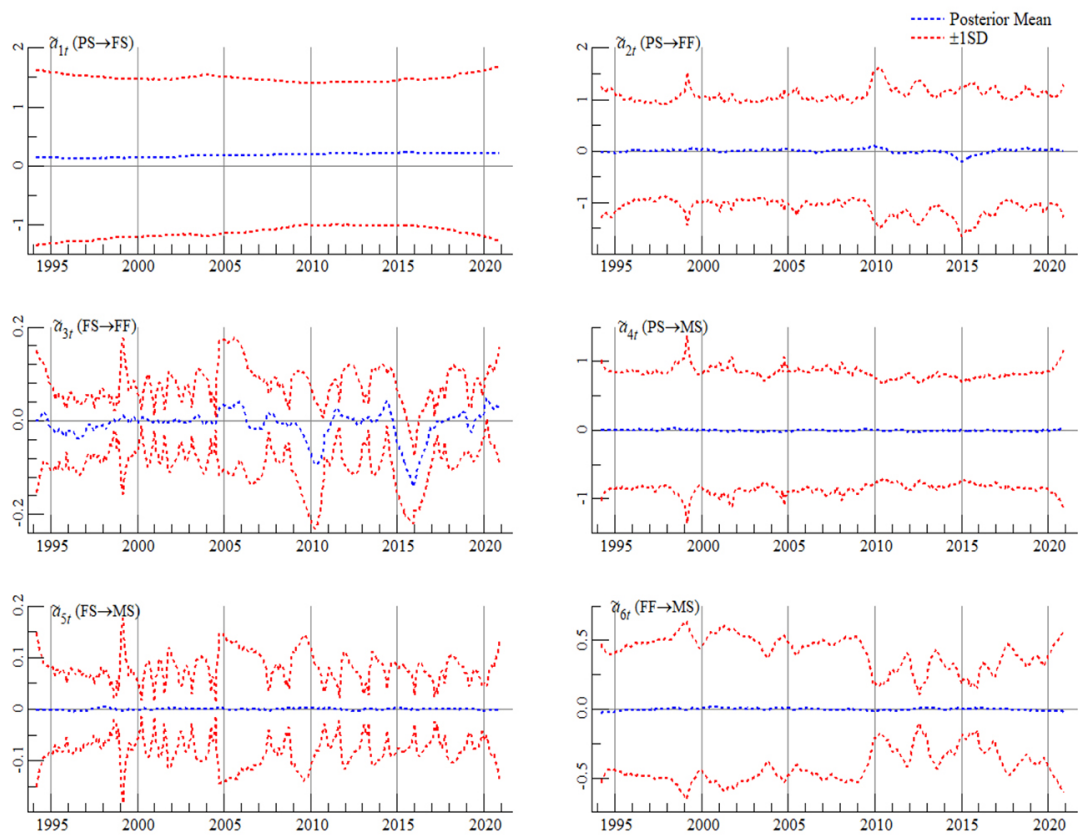

Note: See explanations in Figure A3. 


\section{SUSCRIPCIONES AÑN 2021}

Suscripción anual
Subscriptions rates

All other countries:

Institutions US\$ 42

Individuals $\quad$ US\$ 38

$\$ 17.000$

$\$ 10.000 *$

Estudiantes

$\$ 12.000 \mathrm{c} / \mathrm{u}$

Números sueltos

Single copy rate

US\$ 22

(Includes postage)

* Se debe presentar certificado

de matrícula.

Toda correspondencia puede hacerse al Editor; en cuanto a pedido de publicaciones, puede hacerse mediante cheque o solicitarlas mediante factura proforma a: Facultad de Economía y Negocios,

Universidad de Chile, Campus Andrés Bello, Diagonal Paraguay 257, torre 26, casilla 3861, Santiago, Chile.

Favor enviar comprobante de pago a edejec@fen.uchile.cl notificando suscripción.

Disclaimer

Correspondence should be addressed to Editor, Estudios de Economía.

Make all remittances payable to:

Facultad de Economía

y Negocios, U. de Chile.

P.O. Box 3861, Santiago, Chile.

Please, send a proof of payment to edejec@fen.uchile.cl to notify us about your subscription.

Disclaimer

It is your responsibility to notify the payment to receive the subscription.

Es su responsabilidad notificar el pago para recibir la suscripción. 


\section{$\begin{array}{llllllllll}R & E & V & \text { I } & \text { S } & \text { T } & \text { A } & & \text { D } & \text { E }\end{array}$ ANALISIS ECONOMICO}

CONTENIDO DEL VOLUMEN 36 - Nº 1 - ABRIL DE 2021

\section{ARTICULOS / ARTICLES}

Javier Alejo, Víctor Funes Leal

Ecuaciones de Mincer de parejas bajo un esquema de selección muestral bivariada. Una aplicación al caso argentino

Mincer Equations for couples with Bivariate Sample Selectivity.

An application for Argentina

\section{Miriam Berges, Lucía Echeverría, Juan Ignacio Rodríguez Biasone}

El costo de los niños y su impacto en el presupuesto de las familias.

Un análisis para Argentina

The cost of children and its impact on the family budget. An application to Argentina

\section{Segundo Camino-Mogro, Luis Felipe Brito-Gaona}

Ciclicidad de la política fiscal en Ecuador

Cyclicality of fiscal policy in Ecuador

\section{Ramón A. Castillo-Ponce, Brian Truong,}

María de Lourdes Rodríguez-Espinosa

Dollarization and Economic Interdependence: the Case of Ecuador Dolarización e interdependencia económica: el caso de Ecuador

\section{Walter Cont, Alberto Porto}

Disentangling the distributive impact of fiscal policy Descomposición del impacto distributivo de la política fiscal

\section{ECONOMIC ANALYSIS}

$$
\begin{array}{llllll}
R & \text { E } & \text { V } & \text { I } & \text { E } & \text { W }
\end{array}
$$


Serie de Libros sobre

\section{Banca Central,} Análisis y

\section{Políticas \\ Económicas}

La serie publica trabajos inéditos sobre banca central y economía en general, con énfasis en temas y políticas relacionados con la conducción económica de los países en desarrollo.

"Es un deber para los encargados de las politicas en todas partes estar abiertos a las lecciones que pueden obtener de sus colegas en otros paises, y aceptar que las respuestas que fueron correctas en un momento pueden no serlo bajo nuevas circunstancias. En la búsqueda de respuestas correctas, los análisis y perspectivas contenidos en esta serie serán de gran valor para Chile y para todos los restantes paises".

Anne Krueger,

Fondo Monetario Internacional

\section{Banco Central de Chile}

\section{Para ordenar:}

http:www.bcentral.cl/books/serie.html

bcch@bcentral.cl

Teléfono: (562) 2670-2888

Fax: (562) 2670-2231

Los precios incluyen costos de transporte y están sujetos a cambio sin aviso previo

\section{ANÁlisis EMPíRICO DEL AHORRO} EN CHILE

Felipe Morandé y Rodrigo Vergara, eds.

“...Este libro es una excelente muestra de análisis cientifico severo y apretado en el cual los actores desfilan sucesivamente en el escenario dejando una explicación maciza y coherente del ahorro chileno". Dominique Hachette,

Pontificia Universidad Católica de Chile

Tapa dura, 306 pp. Ch\$ 15.000, US\$40

\section{INDEXATION, INFLATION AND Monetary Policy}

Fernando Lefort y Klaus Schmidt-Hebbel, eds.

“...I am prepared to bet that this book will become indispensable reading for anybody interested in the role of indexation or the macroeconomics of emerging-market economies."

Guillermo Calvo,

Banco Interamericano de Desarrollo

Tapa dura, 316 pp. Ch\$15.000, US\$40

\section{BANKING, FINANCIAL INTEGRATION, AND INTERNATIONAL CRISES}

Leonardo Hernández y Klaus Schmidt-Hebbel, eds.

"...The articles in this book offer an unusually rich and informative perspective on the perils of financial integration, along with the policies and institutions that work and do not work in this process."

Ricardo J. Caballero,

Massachusetts Institute of Technology

Tapa dura, 452 pp. Ch\$ 15.000, US\$ 40

\section{Monetary Policy: Rules AND TRANSMISSION MECHANISMS}

Norman Loayza y Klaus Schmidt-Hebbel, eds.

“...This book is a must read for anyone interested in understanding the contribution of monetary policy to stability, growth and prosperity."

Sebastián Edwards,

University of California, Los Angeles

Tapa dura, 475 pp. Ch\$15.000, US\$40

\section{INFLATION TARGETING: DESIGN, Performance, Challenges}

Norman Loayza y Raimundo Soto, eds.

"This book provides a wide-ranging review of the state of knowledge in this area, including theoretical aspects as well as specific policy issues.... For anybody interested in monetary policy issues the reading of this book is a must!"

Francisco Rosende,

Pontificia Universidad Católica de Chile Tapa dura, $650 \mathrm{pp}$. Ch\$ 15.000 , US\$40 
